\title{
MULTISCALE INTERFACE TAILORING BETWEEN FLAX YARNS AND EPOXY MATRIX BY ZnO NANORODS
}

\author{
F. Sbardella ${ }^{1 *}$, M. Lilli ${ }^{1}$, M. C. Seghini ${ }^{1}$, I. Bavasso ${ }^{1}$, F. Touchard ${ }^{2}$, L. Chocinski-Arnault ${ }^{2}$, I. \\ Rivilla $^{3}$, J. Tirillò ${ }^{1}$, F. Sarasini ${ }^{1}$ \\ ${ }^{1}$ Department of Chemical Engineering Materials Environment, Sapienza - Università di Roma, \& UdR \\ INSTM, Via Eudossiana 18, 00184 Roma, Italy \\ ${ }^{2}$ Institut PPRIME, CNRS-ENSMA-Université de Poitiers, Département Physique et Mécanique des \\ Matériaux, ENSMA, 1, Av. Clément Ader, B.P. 40109, 86961 Futuroscope Fedex, France \\ ${ }^{3}$ Donostia International Physics Center (DIPC), Paseo Manuel Lardizabal 4, 20018 Donostia-San Sebastián, \\ Spain
}

\begin{abstract}
The ideal mechanical performance of a composite is controlled by the level of interfacial adhesion and to overcome the incompatibility issues between plant fibres and polymeric matrices, the surface of flax yarns has been modified by zinc oxide $(\mathrm{ZnO})$ nanostructures. The $\mathrm{ZnO}$ nanorods were synthesized through a lowtemperature hydrothermal treatment, and several parameters have been analysed in order to obtain a uniform and homogeneous $\mathrm{ZnO}$ interphase, such as the number of the seeding cycles, the growth reaction times and the replacement of the growth solution. The results showed that it is possible to obtain highly oriented and well aligned $\mathrm{ZnO}$ nanostructures (by FE-SEM), with an hexagonal wurtzite structure (by XRD) and a high degree of coverage along the whole yarn (by TGA), reducing the number of the seed cycles, with rather long growth times ( 5 hours) and substituting the growth solution at least once during the synthesis. The experimental conditions preserved the breaking force of the yarns, while Single Fibre Fragmentation Tests (SFFT) highlighted a better interfacial adhesion of ZnO-modified flax yarns with epoxy matrix, which displayed a 29 $\%$ reduction in average debonding length relative to untreated yarns.
\end{abstract}

\section{INTRODUCTION}

To limit environmental problems as much as possible, the processing of polymer matrix composites that uses natural fibres as reinforcement has increased significantly in recent years. Low density, low cost, recyclability and biodegradability are the key advantages of plant-based fibres, such as flax, hemp, jute and many others that make them suitable as potential substitutes for glass fibres in composite materials [1-4].

Among all plant-based fibres, flax is considered the strongest one [5] and very interesting for numerous applications due to its low density, ease of handling and wide range of accessibility [6,7]. Flax fibre components include cellulose, hemicellulose, lignin, pectin, waxes and water soluble substances. Cellulose is

${ }^{*}$ Corresponding author: Francesca Sbardella. Tel.: +39 06 44585314. E-mail: francesca.sbardella@uniroma1it 
the main constituent (between 65 and $75 \%$ of the total weight of flax fibres) and is made up of a semicrystalline polysaccharide with a huge amount of hydroxyl groups, which give the fibre a hydrophilic character. The microstructure of flax fibre is extremely complex due to its heterogeneous nature along the length and the different constituents present in variable proportions [8]. For semi-structural applications, the fibres must be aligned and oriented, but the single fibres due to their discontinuity, short length $(<3-30 \mathrm{~mm})$ and random orientation are not useful for the purpose. In order to produce an aligned structure, flax fibres are spun into yarns using conventional textile spinning methods [9].

The important checkpoints in composites are the constituent characteristics and the relative interface. The excellent mechanical properties of the composite are closely linked to the interfacial adhesion which represents the greatest issue in composite materials because the bond between two materials can be unstable or could be damaged [10]. Consequently, an efficient transfer of stress from the matrix to the reinforcing fibre requires a good interfacial bonding. Several experimental methods are used to investigate the interfacial adhesion in polymer composites, such as the microbond test [11], the pull-out test [12], microindentation test [13] and the fragmentation test [14]. Single fibre fragmentation test (SFFT) is one of the most widely used [15], but its application to composites with natural fibres, which are highly heterogeneous in nature, has some limitations, such as the difficulties of applying this method to a single natural fibre and the close dependence on the diameter of the tested fibre, which have been already discussed elsewhere [16].

A serious problem in natural fibre reinforced composite materials is that fibres have a strong polar character that creates incompatibility with most hydrophobic polymer matrices. Therefore, physical and chemical modifications of the fibre surface are often performed [3,17-30]. All these methods displayed a variable influence on the interfacial adhesion between natural fibres and polymer matrix; however, they also highlighted some side effects such as the decrease in the mechanical properties of the fibres. For this reason, a new approach has been sought that preserves the mechanical properties of the fibre itself but at the same time increases the adhesion at the interface in a fibre-reinforced composite. Indeed, to increase the surface area available for bonding and enhance load transfer between fibre and matrix, one possibility is to grow nanowires, nanotubes or whiskers on the surface of the fibre that could protrude into the matrix [31-34]. The whiskering process involves the nucleation and growth of single high-strength crystals such as silicon carbide (SiC) [35], titanium dioxide $\left(\mathrm{TiO}_{2}\right)$ [36], silicon nitride $\left(\mathrm{Si}_{3} \mathrm{~N}_{4}\right)$ [37] and zinc oxide $(\mathrm{ZnO})[38,39]$.

Zinc oxide, in particular, has proved to be of great interest in the scientific community for its distinctive properties, including a wide bandgap of $3.4 \mathrm{eV}$ and relatively large exciton binding energy of $60 \mathrm{meV}$, excellent chemical stability, nontoxicity, and good electrical, optical, and piezoelectric properties [40,41]. $\mathrm{ZnO}$ has three typical crystal structures: wurtzite, zinc blende, and rock salt. The thermodynamically stable phase of $\mathrm{ZnO}$ at ambient temperature and pressure is wurtzite, which shows an hexagonal structure with both $\mathrm{Zn}$ and $\mathrm{O}$ atoms arranged in a hexagonal close-packed pattern and stacked alternately along the c-axis [42,43]. Zinc oxide can occur in one (1D), two (2D) and three-dimensional (3D) structures and the four most common types of $1 \mathrm{D} \mathrm{ZnO}$ nanostructures are nanowires, nanorods, nanobelts, and nanotubes [44]. The variety of nanometric zinc oxide structures means that they can be classified among new materials with potential applications in 
many fields of nanotechnology. It is essential to accurately control their size, shape and surface architecture since the properties of $\mathrm{ZnO}$ strongly depend on its morphology and shape [45,46].

There are several synthesis methods, such as metal organic chemical vapor deposition (MOCVD) [47,48], electrochemical deposition [49,50], sputter deposition [51] and pulse laser deposition [52]. ZnO nanowires have been generally synthesized by chemical or physical vapor deposition but require sophisticated equipment, accurate gas concentration with specific flow rate and most of all are performed with high temperatures $(\geq 350$ ${ }^{\circ} \mathrm{C}$ ), which in the case of flax fibres would degrade the fibres and consequently their properties. Therefore, it is important to find a simple and low temperature method for the synthesis of $\mathrm{ZnO}$ that allows as much as possible the control of the growth parameters of the nanostructures in order to modulate their final morphology. Among the low-temperature methods, there is the hydrothermal process that shows some advantages such as the use of a simple system, a relatively low temperature, a low cost and it is environmentally friendly, as the synthesis is performed in an aqueous growth solution, hence potentially preserving the mechanical properties of the flax fibres $[53,54]$.

In recent years, the hydrothermal process used to grow $\mathrm{ZnO}$ nanostructures has been successful due to its simplicity and mild growth conditions. The hydrothermal growth method generally follows a two-step process, which involves an initial seeding of the $\mathrm{ZnO}$ nanoparticle layer on the surface and a subsequent deposition process of the solution, with consequent development of epitaxial crystals of $\mathrm{ZnO}$ nanostructures $[55,56]$. The morphology of $\mathrm{ZnO}$ can be tailored by changing the growth solution's properties and consequently this method offers new opportunities to engineer the interface for improved strength [41].

The growth of these nanostructures on the surface of the fibres has proven to be useful for increasing the interfacial adhesion between fibre and matrix, at least for synthetic fibres [57,58]. In literature there are very few studies investigating the effect of $\mathrm{ZnO}$ on natural fibres and specifically one is more focused on the antibacterial effect of $\mathrm{ZnO}$ on cellulose-based fibres [59] and the other is focused on the role that zinc oxides have in interfacial adhesion using poly (lactic acid) as a matrix [60]. Therefore, the $\mathrm{ZnOs}$ are of great interest both for the possibility of increasing the interfacial adhesion in composites but also for the ability to add new functionalities to natural fibres, such as antibacterial activity. In this framework, the present work aims to grow $\mathrm{ZnO}$ nanostructures on flax fibres, through a low temperature hydrothermal process, and then investigate their properties as added interface layer between fibres and epoxy matrix. Hydrothermal synthesis is a fairly simple process but as there are several parameters that can influence the morphology of $\mathrm{ZnO}$ as reported in literature [61-63], it was decided to study the influence of some parameters such as the number of seed cycles, the growth times and the replacement of the growth solution, which will be analysed from a chemical and morphological point of view, in order to optimize the hexagonal nanorod-like morphology and to maximize the surface area available to connect with the polymer matrix. In this regard the adhesion quality between flax yarn and epoxy matrix was assessed through the SFFT method adapted to the flax yarn, in terms of interfacial shear strength, critical fragment length and debonding length, comparing the results with the neat flax yarn. 


\section{MATERIALS AND METHODS}

\subsection{MATERIALS}

Individual flax yarns (Linum usitatissimum) were extracted by hand from Biotex fabric, a $2 \times 2$ twill fabric $\left(200 \mathrm{~g} / \mathrm{m}^{2}\right)$, commercialized without any specific sizing and supplied by Composites Evolution (UK). Analytical grade reagents of zinc acetate dihydrate $\left(\mathrm{Zn}\left(\mathrm{CH}_{3} \mathrm{COO}\right)_{2} \cdot 2 \mathrm{H}_{2} \mathrm{O}, 99 \%\right)$, zinc nitrate hydrate $(\mathrm{Zn}$ $\left.\left(\mathrm{NO}_{3}\right)_{2} \cdot 6 \mathrm{H}_{2} \mathrm{O}, 99 \%\right)$, sodium hydroxide $(\mathrm{NaOH}, 99 \%)$ and hexamethylenetetramine (HMTA, 99\%) were obtained from Sigma-Aldrich and used without any further purification. The absolute ethanol $\left(\mathrm{CH}_{3} \mathrm{CH}_{2} \mathrm{OH}\right.$, 99.8\%) was supplied by VWR Chemicals and the $18 \mathrm{M} \Omega \cdot \mathrm{cm}$ Milli-Q water was used through the experimental steps.

The epoxy system including PRIME 27 infusion resin and PRIME 20 slow hardener was delivered by GURIT. The curing process was carried out with a recommended mixing ratio of 100:28 by weight. A post-curing step of $7 \mathrm{~h}$ at $90{ }^{\circ} \mathrm{C}$ was optimized to obtain a fully cross-linked epoxy.

\subsection{ZnO NANORODS SYNTHESIS}

$\mathrm{ZnO}$ nanoparticles were synthesized following the two-step methodology proposed by Galan et al. [56]. In the synthesis are involved two processes: the initial formation of the seed layer and the subsequent growth of $\mathrm{ZnO}$ nanorods. For the synthesis of $\mathrm{ZnO}$ nanoparticle seeds, $1 \mathrm{mmol}$ of zinc acetate dihydrate was dissolved in 80 $\mathrm{mL}$ of ethanol at $50{ }^{\circ} \mathrm{C}$ and vigorously stirred for $5 \mathrm{~min}$. A separate solution of $2 \mathrm{mM}$ sodium hydroxide was dissolved in $100 \mathrm{~mL}$ of ethanol at $50{ }^{\circ} \mathrm{C}$ and stirred vigorously for $5 \mathrm{~min}$. Both solutions were then cooled to room temperature. Upon cooling, $40 \mathrm{~mL}$ of zinc acetate solution was added to $320 \mathrm{~mL}$ of ethanol, and $40 \mathrm{~mL}$ of sodium hydroxide solution was added to $100 \mathrm{~mL}$ of ethanol. The solutions were heated separately to $65^{\circ} \mathrm{C}$ then mixed together under vigorous stirring at $65^{\circ} \mathrm{C}$ for $30 \mathrm{~min}$. The flax yarns were rinsed with ethanol and dried at $150^{\circ} \mathrm{C}$ for $10 \mathrm{~min}$. The $\mathrm{ZnO}$ nanoparticle seeds were coated on the yarns by dipping them into the solution followed by annealing at $150^{\circ} \mathrm{C}$ for $10 \mathrm{~min}$. This step was repeated one (1S) and three times (3S). For the $\mathrm{ZnO}$ nanorods growth process, $3.71 \mathrm{~g}$ of zinc nitrate hexahydrate and $1.75 \mathrm{~g}$ of hexamethylenetetramine were dissolved in $500 \mathrm{~mL}$ of $18 \mathrm{M} \Omega \cdot \mathrm{cm}$ Milli-Q water and heated to $90{ }^{\circ} \mathrm{C}$ under vigorous stirring. Once the solution reached $90^{\circ} \mathrm{C}$, the yarns were immersed in the beaker containing the growth solution. At fixed times, the solution was changed, and the samples were put in another beaker with preheated growth solution. At the end of the growing step, the samples were rinsed with $18 \mathrm{M} \Omega \cdot \mathrm{cm}$ Milli-Q water to remove the presence of precipitates. The fibres were withdrawn at different growth times to characterize their morphologies.

\subsection{CHARACTERIZATIONS}

\subsubsection{Scanning electron microscopy (SEM)}

The morphology of the $\mathrm{ZnO}$ nanostructures was analysed by FE-SEM, a field-emission scanning electron microscope (MIRA3 by Tescan). All specimens were sputter coated with chromium prior to each FE-SEM observation 


\subsubsection{Thermogravimetric analysis (TGA)}

The thermal stability of modified flax yarns as well as the degree of surface coverage were investigated in the temperature range up to $800{ }^{\circ} \mathrm{C}$ using a SetSys Evolution TGA/DSC (Setaram Instrumentation) thermogravimetric analyser. The yarns were placed in an alumina pan and heated at a rate of $10{ }^{\circ} \mathrm{C} / \mathrm{min}$ in argon atmosphere.

\subsubsection{X-ray diffraction $(X R D)$ analysis}

The identification of the crystalline materials was performed by X-ray diffraction (XRD) analysis by means of Philips X'Pert PRO powder diffractometer. XRD spectra were collected in the range of $2 \theta=10^{\circ}-80^{\circ}$ with a step size of $0.02^{\circ}$ and a time per step of $3 \mathrm{~s}$. The employed radiation was monochromatic $\mathrm{Cu}_{\mathrm{k} \alpha}(40 \mathrm{kV}-40$ $\mathrm{mA})$.

\subsubsection{Tensile testing of flax yarns}

A mechanical characterization of the $\mathrm{ZnO}$-modified flax yarns was carried out by tensile tests on single flax yarns. Single yarn tensile tests were performed according to ASTM C-1557 with three different gauge lengths, namely 20,30, and $40 \mathrm{~mm}$. Single yarns were glued onto card tabs with a central window equal to the selected gauge length. Tensile tests were carried out at room temperature in displacement control with a cross-head speed of $2 \mathrm{~mm} / \mathrm{min}$ using a Zwick/Roell Z010 equipped with a $1 \mathrm{kN}$ load cell. Prior to testing, yarns were conditioned in oven at $45^{\circ} \mathrm{C}$ for $24 \mathrm{~h}$ for moisture elimination. Thirty yarns were tested at each gauge length.

\subsubsection{Micro-CT analysis}

Single yarn composite specimens were analyzed by an UltraTom CT scanner by RX Solutions, with a resolution of $1.5 \mu \mathrm{m}$, an accelerating voltage of $50 \mathrm{kV}$, and a beam current of $157 \mu \mathrm{A}$.

$3 \mathrm{D}$ reconstruction was performed on X-ray images acquired from 1120 rotation views over $360^{\circ}$ (approximately $0.32^{\circ}$ rotation step) by using the Avizo 9.0 software [16].

\subsubsection{Single yarn fragmentation test}

The interfacial adhesion between flax yarns and epoxy matrix was evaluated by single yarn fragmentation test. Details of the experimental steps to manufacture the single yarn composite specimens can be found in [16]. Prior to matrix casting, flax yarns were conditioned at $45{ }^{\circ} \mathrm{C}$ for $24 \mathrm{~h}$. Tests were carried out in an Instron E1000 ElectroPuls test machine with a load cell of $2 \mathrm{kN}$ at a crosshead speed of $0.005 \mathrm{~mm} / \mathrm{min}$. The flax yarn diameters (ten measurements along the gauge length), as well as the fragment lengths, were measured by using a ZEISS Axio Imager optical microscope. The loading phase of the test was interrupted at specimen's failure or when the fragmentation saturation level was achieved, defined as no occurrence of new yarn breaks during a subsequent strain increase by $0.5 \%$ [64]. For each family of single yarn composites, at least 10 fragmentation tests were performed. 


\section{RESULTS AND DISCUSSION}

In order to understand the different morphologies that could be obtained with the aforementioned two-stage hydrothermal synthesis methodology, it was initially decided to set the number of seed cycles at 3 (3S) and growth times at 1, 3 and $5 \mathrm{~h}$, while changing the solution every hour. The corresponding morphologies are reported in Fig.1.
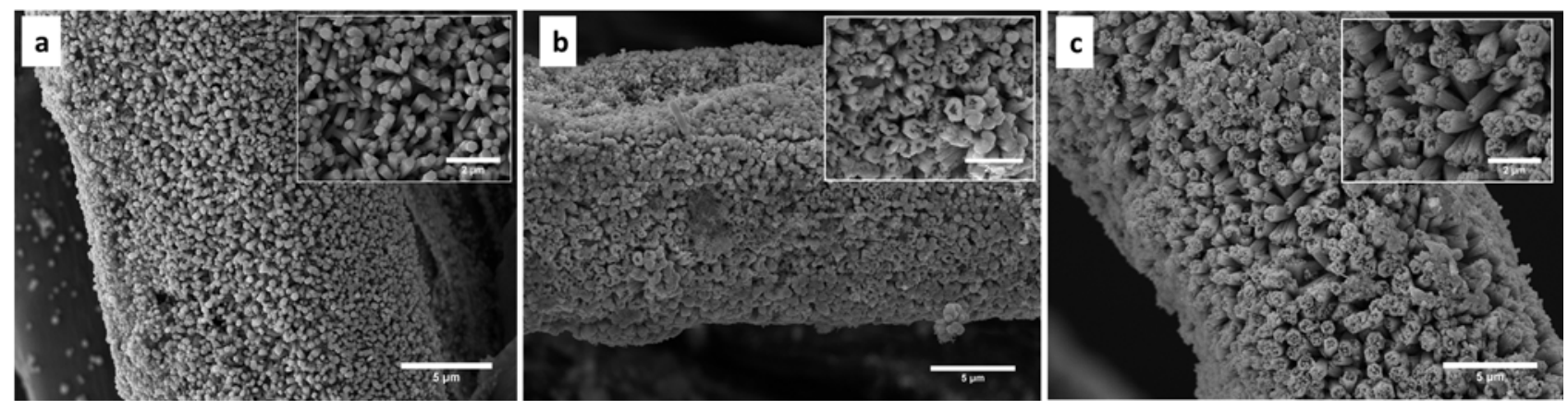

Figure 1. FE-SEM micrographs of ZnO-modified flax yarns with 3 seed cycles and different growth times: (a) 1 hour, (b) 3 hours and (c) 5 hours

From SEM characterizations, it is evident that the flax fibre surface is covered by a continuous and densely packed array of $\mathrm{ZnO}$ nanostructures. The morphologies obtained change with increasing growth time (Fig. 1): from hexagonal rods present in the sample modified at 1 hour (a) to bundles of smaller diameter nanorods with irregular structure for samples after 3 and 5 hours of treatment (b-c). A possible explanation of this effect is related to the seed layer. In fact, seeding of the substrate with $\mathrm{ZnO}$ nanoparticles was found to lower the thermodynamic barrier by providing nucleation sites and thus it is an important parameter to achieve uniform growth of $\mathrm{ZnO}$ nanostructures through hydrothermal process [65]. It was found that the morphology of the $\mathrm{ZnO}$ nanorods is dependent on the thickness of the seed layer and the corresponding crystal size. A thinner $\mathrm{ZnO}$ seed layer leads to a higher surface area of $\mathrm{ZnO}$ nanorods due to the smaller crystal size of the seed layer [62]. In addition, a competition between neighbouring nanorods and preferential growth axis of the crystal needs to be considered. With increasing number of dip-coating cycles, there are many nucleation sites available on the flax surface and the large spatial hindrance that is generated can promote highly compact $\mathrm{ZnO}$ nanostructures, in which a crystal plane of hexagonal $\mathrm{ZnO}$ nanorods might be attached to one another, thus driving the self-assembly in $\mathrm{ZnO}$ bundles (Fig. 1b-c).

To obtain a thinner seed layer and consequently a uniform crystal size morphology, it was decided to change the number of the seed cycles from $3(3 \mathrm{~S})$ to $1(1 \mathrm{~S})$ while varying the growth times from 1 to 5 hours with a replacement of the solution every hour. The effects of changing the number of seed cycles and growth times on the $\mathrm{ZnO}$ morphology are reported in Fig. 2. 

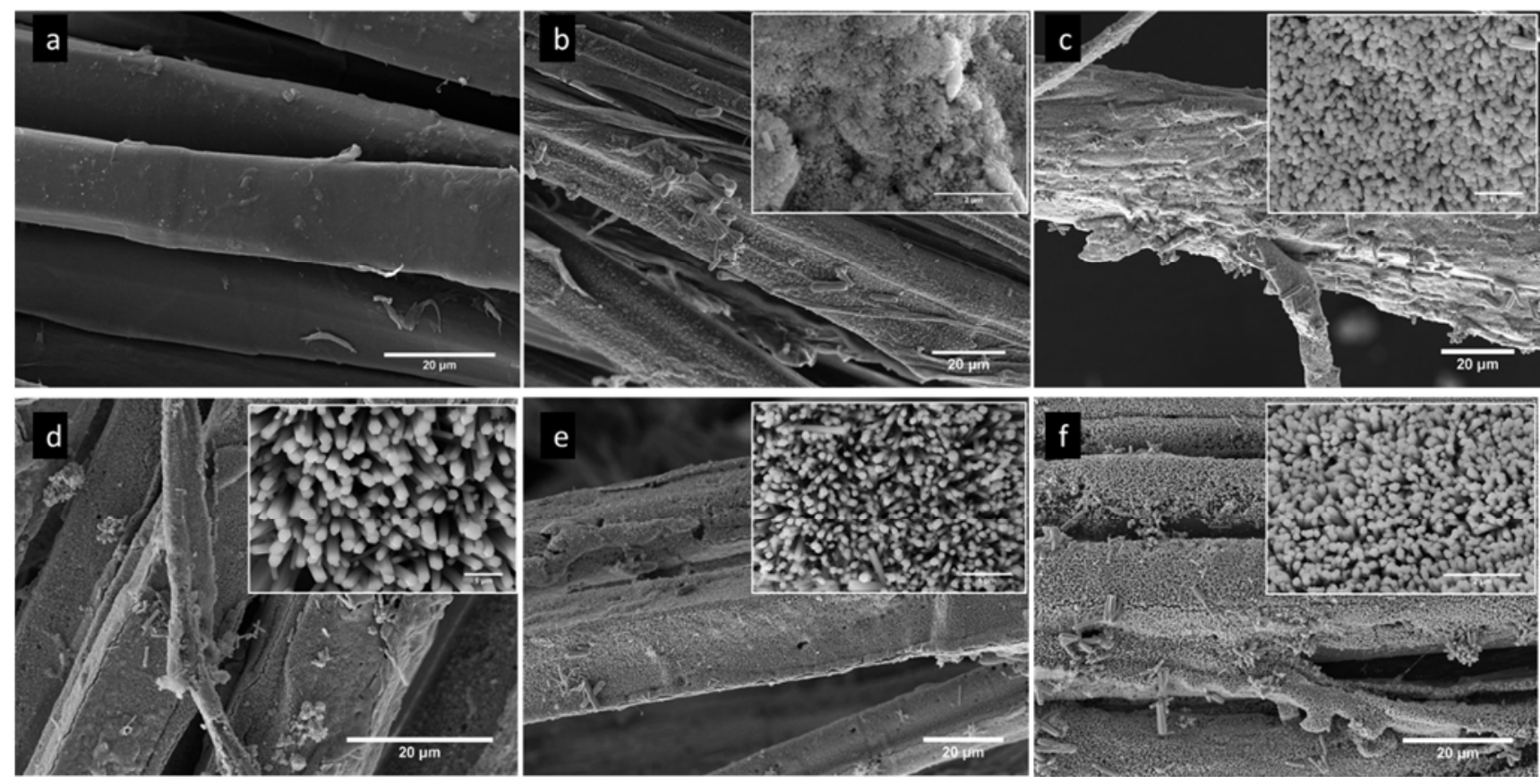

Figure 2. FE-SEM micrographs at different magnifications of flax yarns untreated (a) and treated with $\mathrm{ZnO}$ nanostructures with 1 cycle of seed process: (b) 1 hour of growth time $(20 \mu \mathrm{m}$ and inset $2 \mu \mathrm{m})$; (c) 2 hours of growth time (20 $\mu \mathrm{m}$ and inset $1 \mu \mathrm{m})$; (d) 3 hours of growth time $(20 \mu \mathrm{m}$ and inset $1 \mu \mathrm{m})$; (e) 4 hours of growth time $(20 \mu \mathrm{m}$ and inset $1 \mu \mathrm{m})$; (f) 5 hours of growth time $(20 \mu \mathrm{m}$ and inset $2 \mu \mathrm{m})$

From Fig. 2 it is evident that lowering the thickness of the seed layer and reducing the available nuclei to drive the epitaxial growth of $\mathrm{ZnO}$ crystals influenced the homogeneity of nanorods morphology, ensuring a uniform layer of hexagonal $\mathrm{ZnO}$ nanorods during the whole growth time. Furthermore, the duration of $\mathrm{ZnO}$ growth is an important factor for controlling the size of final nanostructures. As shown in Fig. 2b, in early stages of the growth step $(1 \mathrm{~h})$, oriented structures were not formed. From 2 hours on, there is the onset of the crystals growth with mostly rounded-shape crystals (Fig. 2c). After 3 hours of growth, hexagonal nanorods with vertical orientation were observed (Fig. 2d-e-f). It is evident that the number of seed cycles played a crucial role in obtaining a homogeneous morphology consisting of hexagonal nanorods densely packed with an orientation perpendicular to the surface of the flax yarns. Focusing only on the samples subjected to 2, 3, 4 and 5 hours of treatment, the diameters and lengths of the hexagonal nanorods were measured to understand how the different growth times influence the sizes of the resulting nanorods (Fig. 3). 


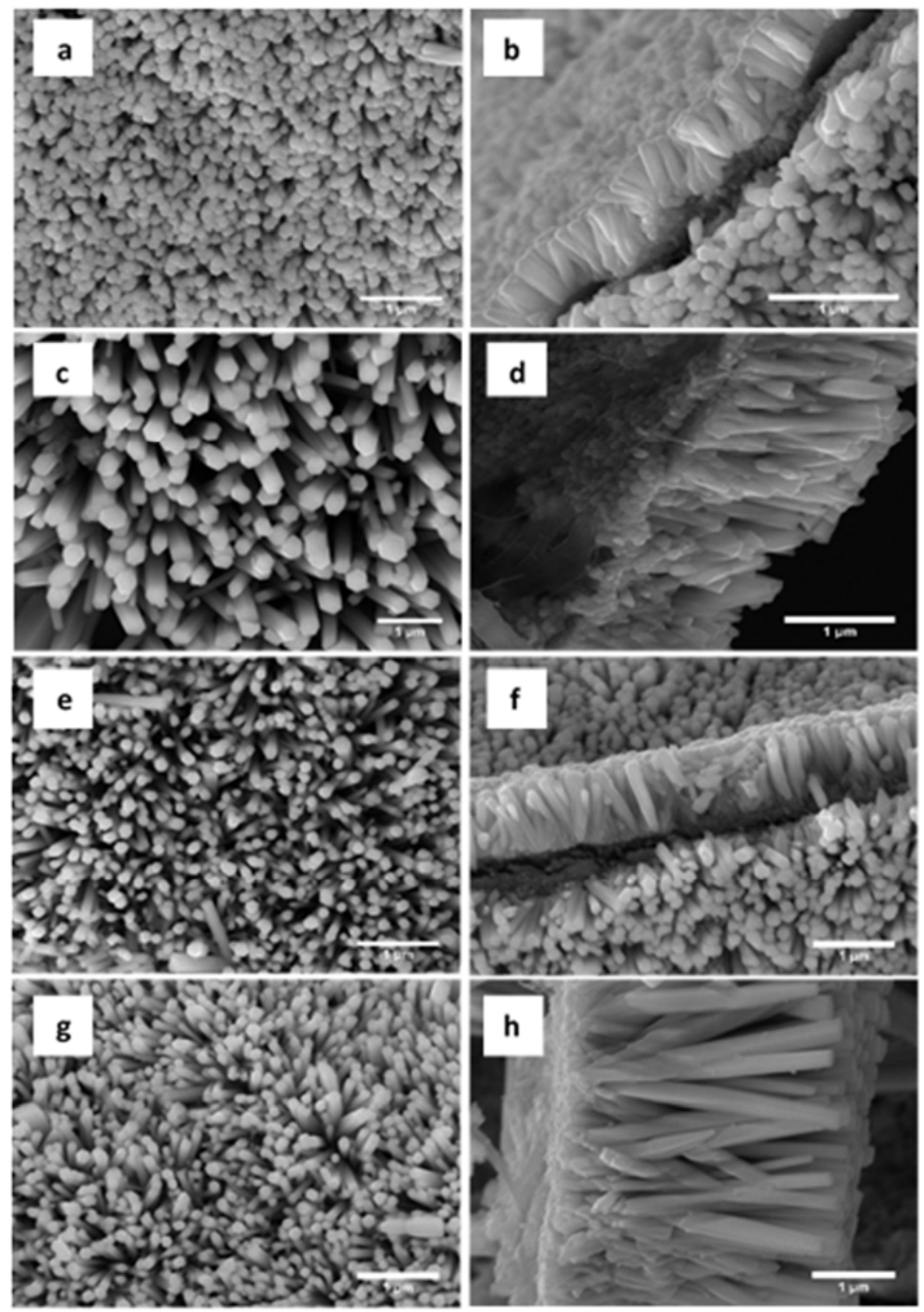

Figure 3. SEM micrographs of the top-down view and of the cross-sectional view of the $\mathrm{ZnO}$ layer for the samples after growth time equal to 2 hours (a-b); 3 hours (c-d); 4 hours (e-f) and 5 hours (g-h)

$\mathrm{ZnO}$ nanorods of about $100-300 \mathrm{~nm}$ in diameter and up to $3 \mu \mathrm{m}$ long were identified only after a few hours of growth. The aspect ratio (length/diameter) is improved by increasing the reaction times (Table 1). In the sample treated at 5 hours, the development of longer nanorods with smaller diameters is evident, obtaining a higher aspect ratio value (14.6), leading to a potential and significant increase in the total surface area of the flax yarns. 
Table 1. Average diameter, length and aspect ratio of $\mathrm{ZnO}$ nanorods at various reaction times

\begin{tabular}{cccc}
\hline Growth time & Diameter $(\mathbf{n m})$ & Length $(\mathbf{n m})$ & Aspect Ratio \\
\hline $\mathbf{2}$ h & $127.83 \pm 17$ & $516 \pm 33$ & 4 \\
$\mathbf{3}$ h & $317.15 \pm 38$ & $1463 \pm 51$ & 4.6 \\
$\mathbf{4}$ h & $150.38 \pm 21$ & $909 \pm 48$ & 6 \\
$\mathbf{5}$ h & $202.53 \pm 25$ & $2958 \pm 92$ & 14.6 \\
\hline
\end{tabular}

As shown in Fig. 4, the X-ray diffraction patterns of neat flax yarns displayed the presence of well-defined peaks at $2 \theta=14.7^{\circ}, 16.4^{\circ}, 22.6^{\circ}$, and $34.5^{\circ}$ that are related to the presence of cellulose I in flax fibres [66]; modified yarns exhibited additional diffraction peaks typical of zinc oxide with hexagonal wurtzite structure (JCPDS 79-0207)[63,67-69], and no peaks related to other substances were detected.
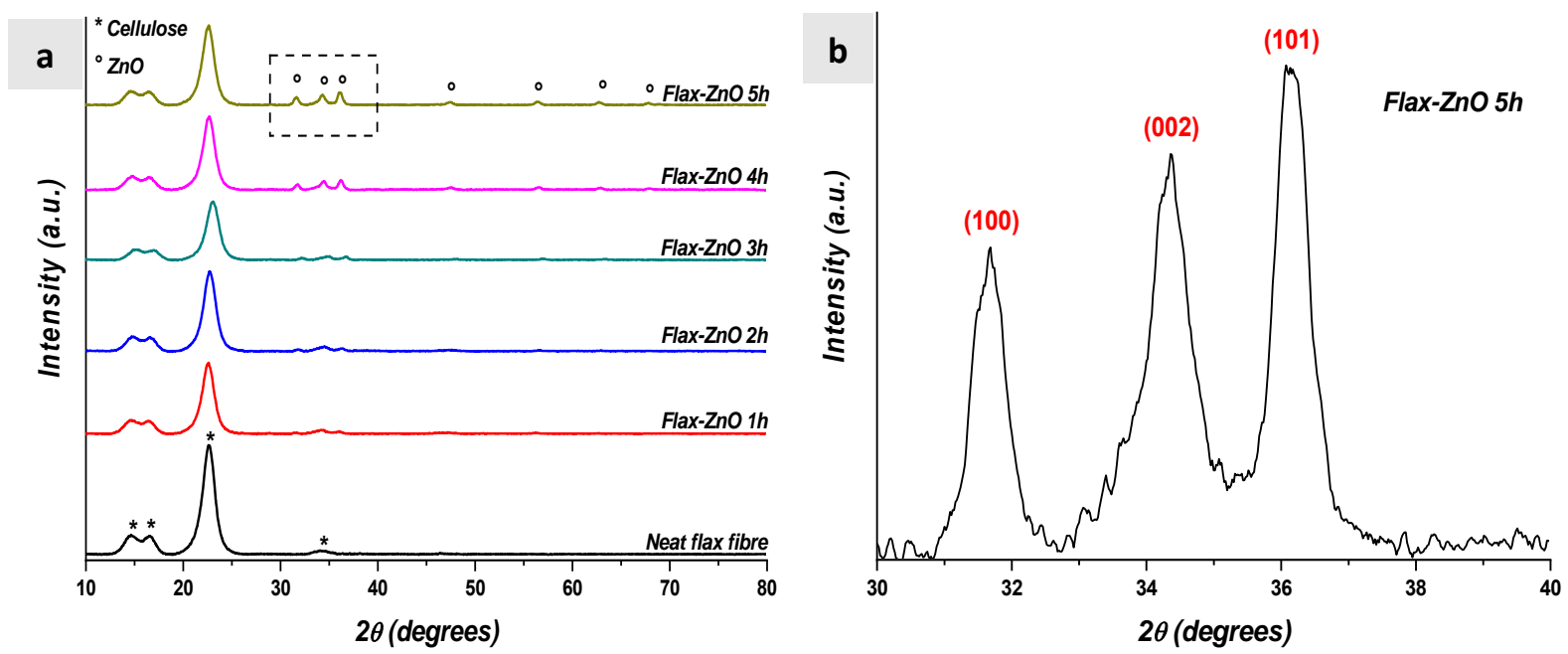

Figure 4. X-ray diffraction spectra for flax yarns as a function of $\mathrm{ZnO}$ growth time

These sharper diffraction peaks with longer growth times are evident, which confirm that the crystallization of hexagonal crystals is favoured at longer reaction times [67]. Furthermore, the sharp diffraction peaks reveal that the $\mathrm{ZnO}$ nanowires possess good crystalline quality. The c-axis of hexagonal cell is normal to substrate, resulting in columnar crystallites that are perpendicular to the substrate surface [68], as it is also confirmed by SEM micrographs (Fig. 3).

The number of seed cycles synergistically with longer reaction times seem to play a fundamental role in the final morphology obtained; indeed lowering the number of seed cycles, from three to one, and extending the growth time $(5 \mathrm{~h})$ appear to favour the formation of more regular and ordered nanostructures (hexagonal wurtzite nanorods), without the formation of other less common morphologies (bundles of smaller diameter nanorods, Fig. 1) as confirmed by SEM micrographs and XRD results.

In order to obtain a final product with good mechanical properties and a high interfacial adhesion, it is necessary to have not only a regular and homogeneous morphology, but also a high degree of $\mathrm{ZnO}$ coverage 
over the entire yarns. From the SEM micrographs, the samples treated for 3-4-5 hours (Fig. 3d-e-f) showed the highest degree of coverage, probably due to the longer reaction times [41]. To confirm this hypothesis, TGA analysis was performed on neat flax yarns and on the treated samples at different reaction times (1-2-34-5 hours) in order to determine the thermal stability of ZnO-flax samples (Fig. 5).
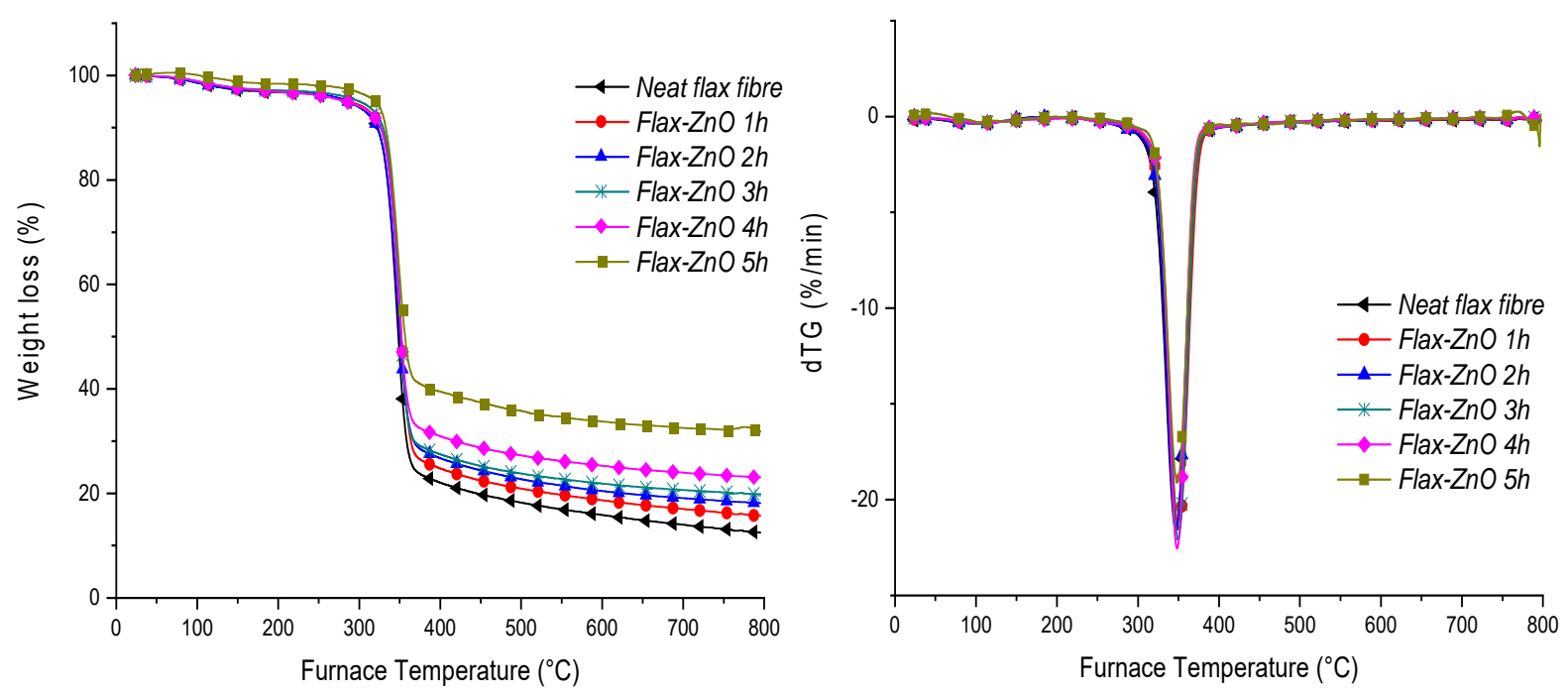

Figure 5. TGA and dTG thermograms of the different samples coated with $\mathrm{ZnO}$ at different growth times

The main weight loss detected by TGA is between $250-450{ }^{\circ} \mathrm{C}$ and is related to degradation of the hemicellulose and cellulose present in flax fibres [70]. The maximum degradation temperature is not significantly affected by the presence of $\mathrm{ZnO}$ nanostructures, with the exception of the onset of degradation, which was shifted to higher temperatures especially after 5h-growth. This is likely to be ascribed to the heat shielding effect promoted by the presence of $\mathrm{ZnO}$ nanorods. The amount of $\mathrm{ZnO}$ grown on the surface of the flax yarns was calculated from the difference in residual weight of the nanorod-decorated flax yarns and the neat flax. The TGA analysis shows that the highest residue mass (32\%) is reached for the sample treated for $5 \mathrm{~h}$, confirming that the content of $\mathrm{ZnO}$ nanorods attached to the flax surface increased with reaction time. In comparison with the residual mass of the neat sample (12\%), yarns subjected to a $5 \mathrm{~h}$-treatment reached a final amount of $20 \%$ of zinc oxides, value in agreement with results available in literature [71] and indeed even higher, as in the case of the work by Yang et al. [65] where it is reached an amount of $16.7 \%$ on sisal fibres with 6 cycles of seeding and 10 hours of growth. Moreover, there is a direct correlation between the reaction times and the residual mass: at shorter times corresponds a lower residual mass, indicating that the flax yarns are not densely covered with $\mathrm{ZnO}$ nanorods, as confirmed also by FE-SEM micrographs (Fig. 2). Tensile properties of flax yarns are essential when considering their use as reinforcement in polymer composites. The mechanical properties of natural fibres are influenced by many factors, including the plant origin and growth conditions, fibre extraction method, fibre diameter, fibre surface treatments, humidity (RH), 
etc. Single yarn tensile tests were performed on the commercial flax yarns (20 mm of gauge length) and on the treated yarns at different reaction times. The results are reported in Table 2.

Table 2. Breaking force as a function of growth time for flax yarns as obtained from single yarn tensile tests

\begin{tabular}{cc}
\hline Flax yarns & $\mathbf{F}_{\text {MAX }}(\mathbf{N})$ \\
\hline Neat flax yarn & $22.97 \pm 3.94$ \\
Flax-ZnO 1h & $18.90 \pm 4.28$ \\
Flax-ZnO 2h & $16.42 \pm 3.29$ \\
Flax-ZnO 3h & $21.12 \pm 4.18$ \\
Flax-ZnO 4h & $16.55 \pm 3.07$ \\
Flax-ZnO 5h & $23.38 \pm 3.91$ \\
\hline
\end{tabular}

Considering the natural variability of the mechanical properties of natural fibres [8], in this case no significant variations in terms of breaking force $(\mathrm{N})$ between neat flax yarns and treated ones were detected, thus suggesting that the low-temperature hydrothermal treatment is able to preserve the mechanical behaviour of natural fibres.

In conclusion, the treated flax yarn that shows the best results in terms of morphology, degree of $\mathrm{ZnO}$ coverage with a uniform hexagonal wurtzite structure and that maintains good mechanical properties is the sample treated for $5 \mathrm{~h}$, with the change of the growth solution every hour and one seed cycle (1S).

However, Amin et al. [41] reported that during the reaction time, the $\mathrm{OH}^{-}$would continuously hydrolyse in the water solution from HMTA up to a certain time when $\mathrm{OH}^{-}$would be consumed, thus it appears useful to investigate if there is an effect produced by the replacement of a new growth solution. Since the sample that has been treated with 1 seed cycle, 5 hours of growth time and with changes every hour (hereafter labelled as Flax-ZnO 5h_1), has proved to be the best formulation, it was decided to study the effect of the growth solution, adding two new formulations by keeping constant the time at 5 hours: one sample is without any refill of the solution (Flax-ZnO 5h_0) and the other with only one change after $2.5 \mathrm{~h}$ (Flax-ZnO 5h_2.5). The resulting morphologies were analysed by FE-SEM and the results are shown in Fig. 6
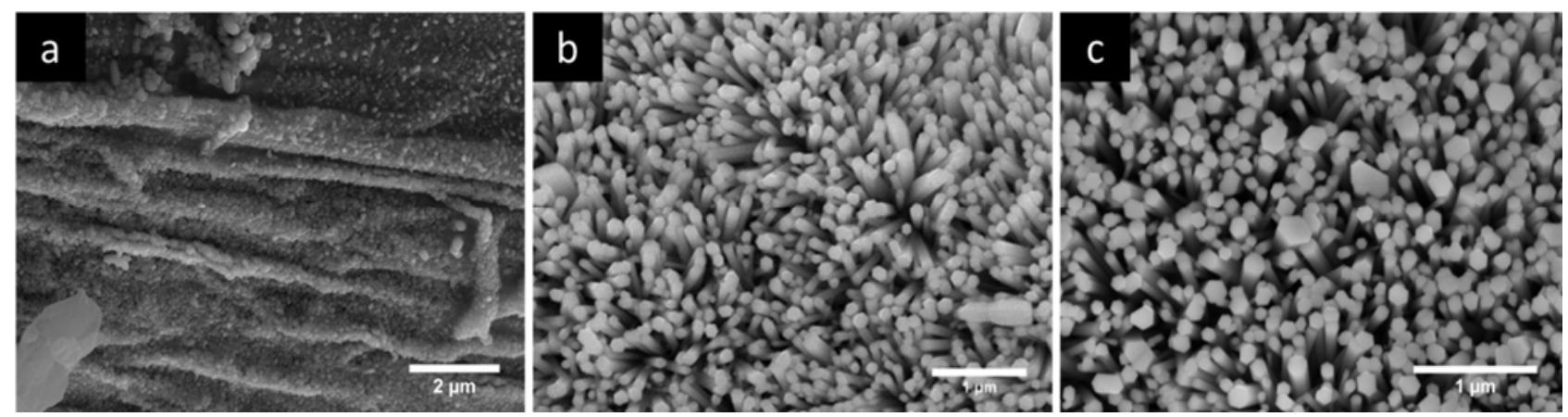

Figure 6. SEM micrographs of flax yarns as a function of growth solution replacement: (a) Flax-ZnO 5h_0, (b) Flax-ZnO 5h_1 and (c) Flax-ZnO 5h_2.5 
Morphology was significantly affected by the replacement of a new growth solution. Fig. 6a shows the formation of indefinite round shaped nanoparticles that demonstrate that the replacement of the solution, with these synthesis conditions, is necessary to grow hexagonal $\mathrm{ZnO}$ nanorods on the yarn surface. In Fig. $6 \mathrm{~b}$ and c, with the refilling of the growth solution every hour and after 2.5 hours, respectively, the formation of the $\mathrm{ZnO}$ hexagonal nanorods is evident. In both cases, the $\mathrm{ZnO}$ nanorods settle uniformly on the flax surfaces but it is also evident that the coverage density in the Flax-ZnO $5 \mathrm{~h} \_2.5$ sample is greater, confirmed by the higher value of aspect ratio (15.4 vs. 14.6 for Flax-ZnO 5h_1 sample, Table 1) and moreover, the nanorods are more vertically aligned, thus ensuring a higher interconnection with the matrix in polymer composites. Since the synthesis conditions seem to have been optimized in the latter case (Flax-ZnO 5h_2.5), their mechanical properties were investigated in detail. For this reason, it was decided to perform the single yarn tensile test with three different gauge lengths $1_{0}(20-30-40 \mathrm{~mm})$. The mechanical properties of the yarns are reported in Fig. 7.

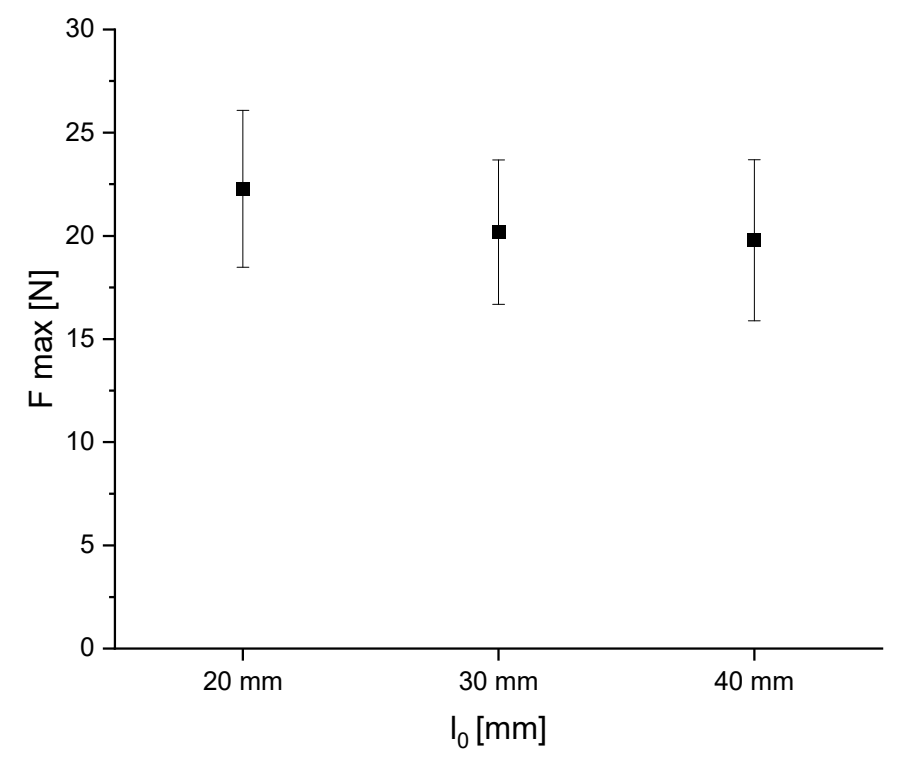

Figure 7. Breaking force as a function of gauge length for the sample Flax-ZnO 5h_2.5

Generally, the tensile strength decreases with an increase in fibre length [72]: the longer the fibre, the higher its probability of containing a defect (e.g. kink bands). As the test length increases, the number of weak links or imperfections also increases, thus resulting in reduction in tensile strength [73]. In the present case, gauge length does not seem to adversely affect, in a significant way, the tensile properties of flax yarns. Fig. 8 shows a comparison of peak forces for flax yarns, tested with a gauge length of $20 \mathrm{~mm}$, with the optimized $\mathrm{ZnO}$ nanostructures. 


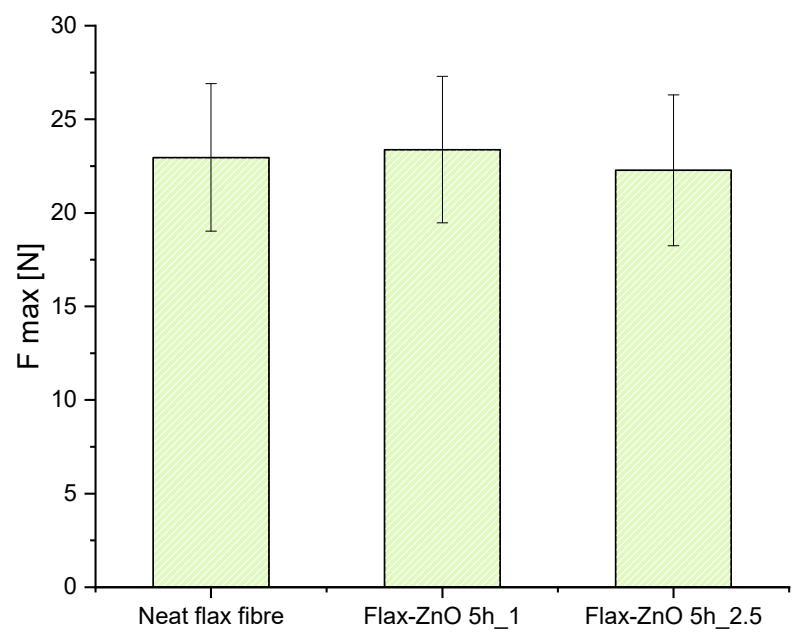

Figure 8. Breaking force for neat flax yarns, Flax-ZnO 5h_1 and Flax-ZnO 5h_2.5

Comparing the results from single yarn tensile test, it is evident that the steps involved in the hydrothermal treatment for the surface modification with hexagonal $\mathrm{ZnO}$ nanorods do not sacrifice the tensile properties of the underlying fibre, thus suggesting the use of $\mathrm{ZnO}$-flax yarns as reinforcement in composite materials.

In order to understand, in terms of interfacial adhesion, the effect that zinc oxides have on the yarn surface when they are in contact with a polymer matrix, the Single Fibre Fragmentation Test (SFFT) was performed on the sample Flax-ZnO 5h_2.5. The test was carried out following the indications provided by Seghini et al. [16] and taking into account the limitations that this methodology has when applied to natural fibres. Interfacial testing has been traditionally associated with the extraction of the interfacial shear strength that requires a certain degree of homogeneity in order to be applicable, especially in terms of fibre diameter. In fact, the main problem in the case of natural fibre composites is the high heterogeneity, with very variable diameter not only between different fibres, but also within the same fibre [74].

In 1965, Kelly and Tyson [75] estimated the average interfacial shear strength in a model single fibre composite as (Eq. 1):

$\tau=\frac{\sigma_{f}\left(\mathrm{l}_{\mathrm{c}}\right) \mathrm{d}}{2 \mathrm{l}_{\mathrm{c}}}$

where $\tau$ is the interfacial shear strength, $\sigma_{f}\left(l_{c}\right)$ is the fibre strength at a length equal to the critical fibre length, $l_{c}$ is the critical fragment length and $d$ is the fibre diameter. This equation is valid only assuming a constant shear stress at the filament/matrix interface; this is true only for a very ductile matrix and a brittle fibre, thus ensuring a full debonding/yielding of the fibre fragments. From Eq. 1 it is necessary to identify the critical fibre length $\left(l_{c}\right)$ and the fibre strength at the critical fibre length $\left(\sigma_{f}\left(l_{c}\right)\right)$; assuming that the fibre lengths follow a normal distribution, then the critical fibre length is estimated from the mean fibre fragment length by using Eq. 2:

$l_{C}=\frac{4}{3} \bar{l}$ 
In Fig. $9 \mathrm{~b}$ is reported an example of a typical optical micrograph obtained for the Flax-ZnO 5h_2.5 fragmented flax yarn. The yarn diameter and fragment lengths were measured in the gauge length region of the specimen (Fig. 9a). The fragment lengths have been determined as the average values between the internal and the central points of the breaking zones, moreover, around each yarn break, the length of the black zone (debonding length) observed on micrographs has also been measured (Fig. 9b) [16].
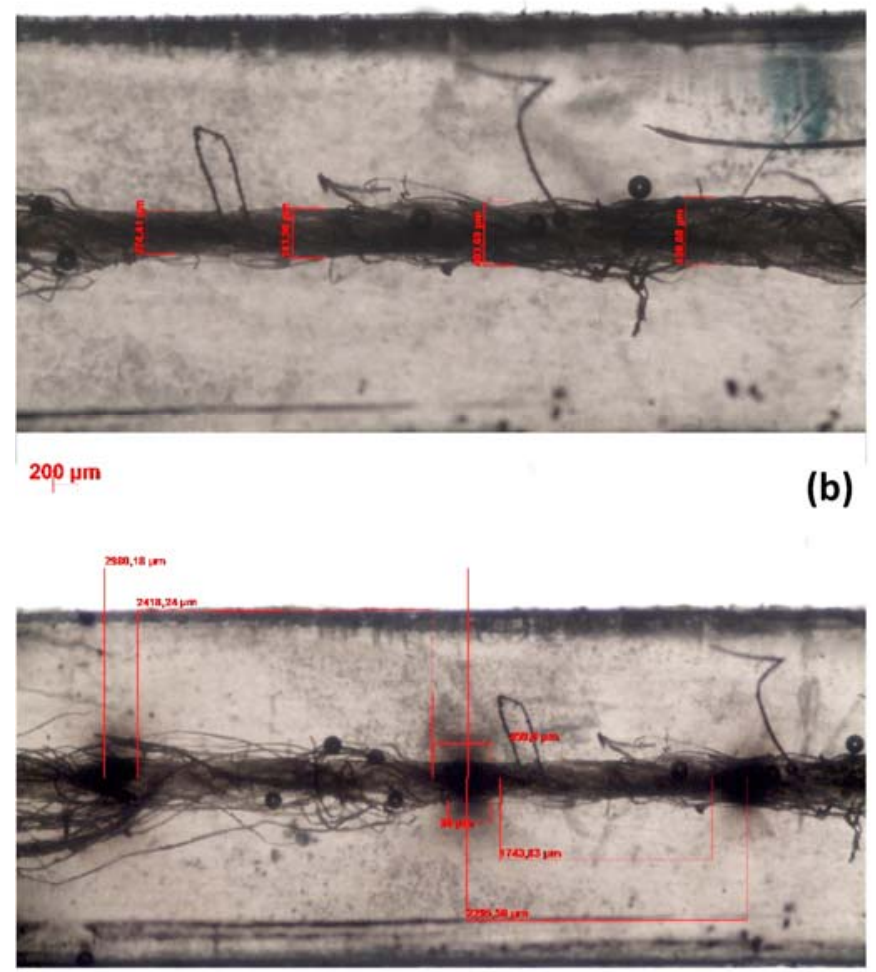

Figure 9. Typical optical micrographs obtained for the sample Flax-ZnO 5h_2.5, before (a) and after (b) the fragmentation test. In (a) there are the measurements of the yarn diameter and in (b) are reported the measurements of the fragment lengths and debonding lengths

In Fig. 9 it is clear the heterogeneity of the diameter in flax yarns; in the case of SFFT applied to natural fibres, one great concern is related to the inhomogeneities in the diameter measurements, which are strictly associated with the interfacial shear stress (Eq. 1) and could lead to wrong estimation of the IFSS values.

The next step is the calculation of the fibre strength at the critical length, $\sigma_{f}\left(l_{c}\right)$. This step is much more complicated than estimating the critical length, since it is difficult to perform experimental measurements of the resistance of the individual yarns at these short lengths (often around few millimetres) and most analyses extrapolate the average strength from resistance distribution data obtained at greater lengths. According to the procedure proposed by El Asloun et al. [76], taking into account that the mean strength $\sigma_{f}$ is given by (for a two-parameter Weibull distribution) Eq. 3: 
$\sigma_{f}=\sigma_{0} l^{-\frac{1}{m}} \Gamma\left(1+\frac{1}{m}\right)$

and taking the logarithm of the Eq. 3:

$\ln \sigma_{f}=-\frac{1}{m} \ln l+\ln \left[\sigma_{0} \Gamma\left(1+\frac{1}{m}\right)\right]$

where $m$ and $\sigma_{0}$ are the shape and the scale parameters of the equivalent Weibull distribution, respectively, $l$ the gauge length, $\sigma_{f}$ the tensile strength and $\Gamma$ the Gamma function. Linear extrapolation by using Eq. 4 can provide the tensile strength of a flax yarn at a given gauge length. It is seen that a graph $\ln \left(\sigma_{f}\right)$ plotted against $\ln (l)$ should be linear with a slope $(-1 / \mathrm{m})$. Thus, in this work tensile tests for the Flax-ZnO 5h_2.5 were performed at three different gauge lengths, specifically at 20-30-40 mm, obtaining a linear graph with the slope $-\frac{1}{m}=-0.1798$.

This linear extrapolation method was used to determine the yarn strength at a length equal to the critical yarn length, $\sigma_{f}\left(l_{c}\right)$, and then the IFSS value was calculated using Eq. 1 for the ZnO-modified flax yarn in epoxy matrix (Table 3). In this table are also included, as a reference, the results obtained from Seghini et al. [77] regarding the SFFT for neat flax yarns and epoxy matrix.

Table 3. Diameters, critical length, debonding length and interfacial shear strength values for $\mathrm{ZnO}$ flax/epoxy single composite and for neat flax/epoxy single composite

\begin{tabular}{ccccc}
\hline & Diameter $[\boldsymbol{\mu m}]$ & $\mathbf{l}_{\mathbf{c}}[\boldsymbol{\mu m}]$ & $\mathbf{l}_{\text {debonding }}[\boldsymbol{\mu m}]$ & IFSS [MPa] \\
\hline NEAT FLAX YARN/EPOXY & $248.33 \pm 33.91$ & $2687 \pm 631$ & $444 \pm 49$ & $19.3 \pm 3.7$ \\
ZnO-FLAX YARN/EPOXY & $336.52 \pm 46.59$ & $2657 \pm 426$ & $314 \pm 49$ & $12.7 \pm 2.4$ \\
\hline
\end{tabular}

In Table 3, the IFSS value obtained for the $\mathrm{ZnO}$ treated flax yarn is lower than the IFSS value of the untreated flax yarn, therefore suggesting that the treatment with $\mathrm{ZnO}$ did not increase the interfacial adhesion between yarn and polymer matrix. Since this value strictly depends on the diameter of the yarn (Eq. 1), when applied to natural fibres, the non-homogeneity in the diameters must be considered, both between the different fibres analysed and within the same fibre. Furthermore, for the $\mathrm{ZnO}$-treated samples, the increase in diameter (336.52 $\mu \mathrm{m}$ vs $248.33 \mu \mathrm{m}$ for neat flax) is due to the presence of $\mathrm{ZnO}$ on the yarn surface and to the possible swelling and untwisting that the yarns experience during the hydrothermal treatment. An increase in the average diameter of yarns results in a reduction in the tensile strength value, thus explaining the decrease in the IFSS values found for the $\mathrm{ZnO}$-flax/epoxy system compared to untreated system [78].

These considerations suggest that the use of only the value of interfacial shear strength can be misleading for natural fibres in an attempt to determine whether or not an increase in interfacial adhesion occurs. To avoid the uncertainties deriving from the determination of the numerical value of the interfacial shear strength, it must be considered that also the critical fibre length plays a fundamental role in the measurement of the IFSS (Eq. 1), providing information related to the quality of the adhesion at the interface in a composite. Indeed, shorter fragments indicate that the efficiency of the interfacial stress has been improved, achieving a good stress transfer at the interface. As reported in Table 3, the fact the $l_{c}$ values are slightly lower for modified 
yarns, confirm that the IFSS value obtained leads to erroneous considerations about the degree of interfacial adhesion.

Furthermore, another very important parameter to consider is the debonding length (Table 3). In composite materials, the bonding at the interface can govern the mechanical properties of the entire composite. As Kim et al. [10] reported, the debonding zone is usually symmetric on both sides of the fibre break site. It is small for strong interfacial bonding but can be large for the weak interfacial bonds. In the present case, the measurements of $l_{\text {debonding }}$ show that the debonding phenomena for the $\mathrm{ZnO}$ modified flax yarn are of lower importance than for the neat flax yarn $(314 \mu \mathrm{m}$ vs. $444 \mu \mathrm{m})$. This result is consistent with the critical yarn length values previously reported (Table 3 ) and it highlights that the $\mathrm{ZnO}$ nanorods can successfully promote the adhesion of flax yarns with the epoxy matrix. To better understand this effect, a morphological investigation of the fracture surface after the single yarn fragmentation test was performed using FE-SEM (Fig. 10 and Fig. 11).

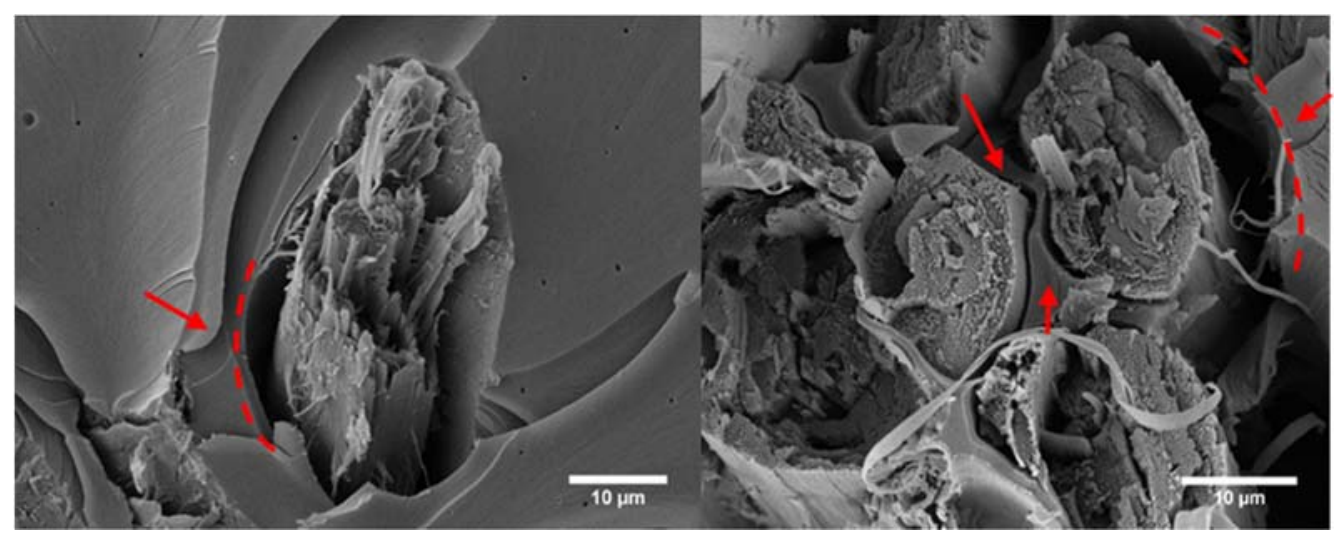

Figure 10. FE-SEM-micrographs showing the fracture surface for neat flax/epoxy single yarn composites

From the SEM micrographs shown in Fig. 10, it is evident that the epoxy matrix and the untreated flax yarns are not connected to each other, as evidenced by the significant gaps indicated by the red arrows. 


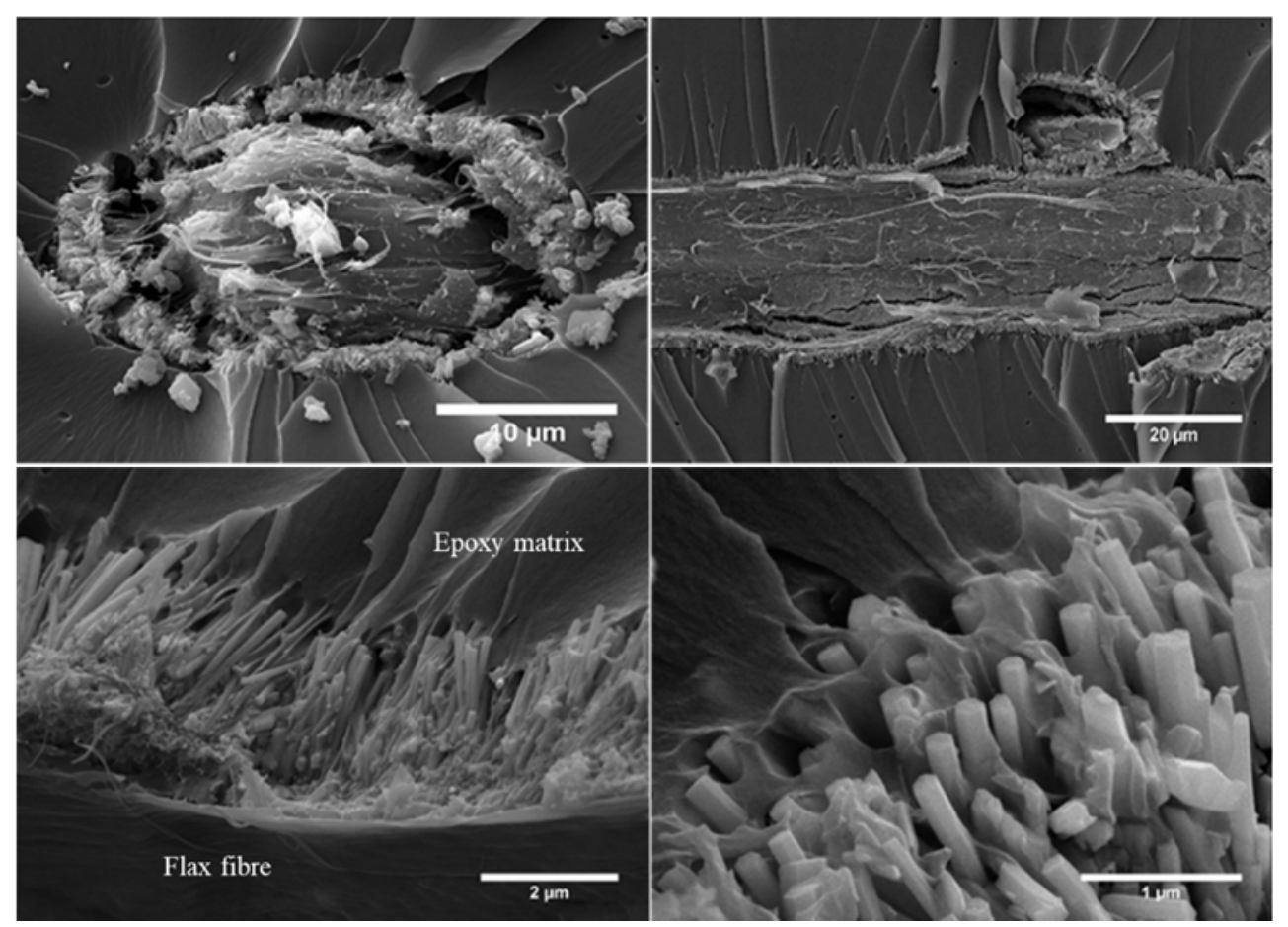

Figure 11. FE-SEM-micrographs showing the fracture surface for $\mathrm{ZnO}$-flax/epoxy single yarn composites

Instead, in the case of $\mathrm{ZnO}$ flax fibre (Fig. 11), it is shown how the modification of the surface with nanorods increased the compatibility with the polymer matrix without any visible presence of extended debonding zones. This also confirms the values obtained from the debonding and critical length measurements (Table 3), which are lower than the untreated yarn. Hence, it is clearly demonstrated that zinc oxide nanostructures on the fibre surface have the ability to protrude into the matrix, creating a bridge between the yarn and the epoxy matrix. The increased interfacial adhesion is to be ascribed to an interlocking effect created by the $\mathrm{ZnO}$ nanorods, favoured by the larger specific surface of modified flax yarns. The morphological investigation pointed out also that what prevented a further enhancement is the failure at the yarn/ZnO interphase, which is a critical parameter that governs the fibre/matrix interfacial adhesion. Ehlert et al. [79], when investigating the adhesion of $\mathrm{ZnO}$ nanorods and carbon fibres, found that manipulating the surface chemistry of the fibres can significantly increase the link between the $\mathrm{ZnO}$ interphase and the carbon fibres. In this regard, the presence of oxygen functional groups including hydroxyl, carbonyl, and carboxylic acid groups, can be particularly beneficial. All these observations suggest the possibility of pre-treating the flax yarns to increase the bond with the $\mathrm{ZnO}$ nanorods.

The high resolution microtomography analysis of fragmented samples highlighted that the $\mathrm{ZnO}$ modification is able to effectively produce a uniform surface coating on flax yarns (Fig. 12a, bright areas). 

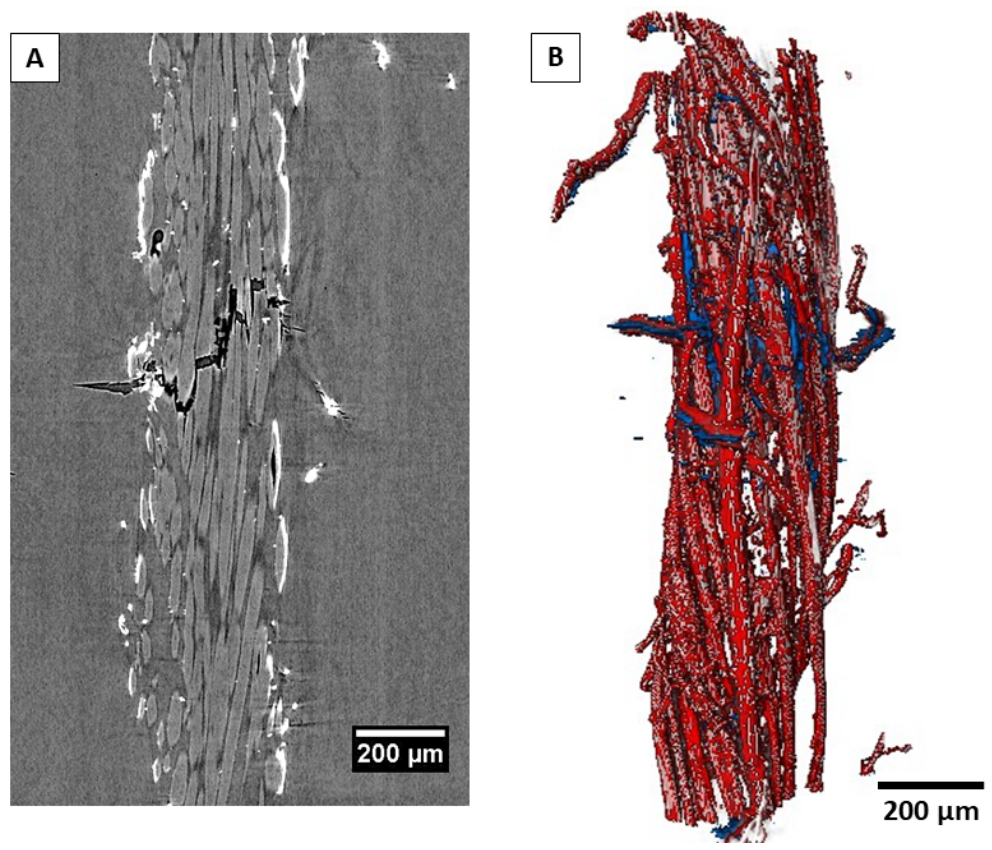

Figure 12. Micro computed tomography observation for the ZnO-modified flax yarn/epoxy matrix. (A) High resolution micro-CT image of the flax yarn embedded in the epoxy resin; (B) Volumetric reconstruction of the flax yarn and the fracture zone: the flax yarn is represented in dark grey, the fracture zone in blue and the $\mathrm{ZnO}$ coating in red

From Fig. 12, it is noted that the flax yarn is characterized by a homogeneous coating of zinc oxides over its entire surface and that the deposition of the $\mathrm{ZnO}$ coating occurs only on the outermost surface of the yarn, without being able to penetrate inside the yarn. Using the AVIZO 9.0 software, it was possible to perform a 3D reconstruction of the fracture zone distribution along the flax yarn. In order to simplify the identification, the dark grey has been used for yarn representation, and the blue and red colours have been chosen for the fracture zone and the $\mathrm{ZnO}$ coating, respectively. The 3D reconstruction for the $\mathrm{ZnO}$ modified flax/epoxy resin specimen shows that there is very limited debonding between the yarn and the polymer matrix that, along with the presence of matrix cracks, support the increase in compatibility and the enhancement of the interfacial adhesion between flax yarns and matrix, making them suitable as reinforcement in fibre reinforced polymer matrix composites.

\section{CONCLUSIONS}

In this study, we investigated the properties of $\mathrm{ZnO}$ nanorods that were successfully grown on the surface of flax yarns using a low-temperature hydrothermal method to improve their interfacial compatibility with polymer matrices. The seeding layer and the reaction times play a crucial role in the final morphology obtained. Lowering the number of the seeding cycles, from three to one, was found to be necessary to obtain homogeneous morphologies. XRD analysis showed the characteristic peaks of crystalline $\mathrm{ZnO}$ and the intensity of the peaks increased with increasing growth time, without altering the cellulosic structure of flax yarns and their thermal stability. The degree of coverage increased as a function of the growth time, as 
confirmed by the residual weight obtained by TGA, compared to untreated flax yarns. Hydrothermal treatment preserved the tensile properties of the $\mathrm{ZnO}$ coated yarns, while the replacement of the growth solution at welldefined intervals was found to significantly affect the resulting $\mathrm{ZnO}$ morphology. In this regard, the best condition can be achieved by changing the solution every 2.5 hours for a total growth time of 5 hours. The characterization of the adhesion properties between flax yarns and epoxy resin was performed by SFFT test adapted to the yarn scale. Fragmentation tests allowed the determination of the adhesion quality between $\mathrm{ZnO}$ flax yarn and epoxy matrix, highlighting reductions in the debonding and critical fragment length values after the modification with $\mathrm{ZnO}$ nanorods. The FE-SEM micrographs of the fracture surface and the 3D reconstruction of the yarn provided clear evidence of the uniform coating present on the outermost surface of the flax yarns, which promoted an effective interlocking mechanism with the epoxy matrix. Surface modification with the addition of a layer of $\mathrm{ZnO}$ nanorods proved to be an excellent and facile approach to improve the quality of the interfacial adhesion in natural fibre composites, even if the adhesive failure of the nanorods array suggests the need to modify the flax surface chemistry for further improvements. 


\section{REFERENCES}

[1] Carvalho H, Salman H, Leite M. Natural Fibre Composites and Their Applications : A Review. J Compos Sci 2018;2:1-20. doi:10.3390/jcs2040066.

[2] Dong C. Review of natural fibre-reinforced hybrid composites. J Reinf Plast Compos 2018;37:33148. doi:10.1177/0731684417745368.

[3] Mohanty AK, Misra M, Drzal LT. Surface modifications of natural fibers and performance of the resulting biocomposites : An overview. Compos Interfaces 2012;8:313-43.

doi:10.1163/156855401753255422.

[4] Kabir MM, Wang H, Aravinthan T, Cardona F, Lau K-T. Effects of Natural Fibre Surface on Composite Properties : a Review. Energy, Environ Sustain 2007:94-9.

[5] Bos HL, Van Den Oever MJA, Peters OCJJ. Tensile and compressive properties of flax fibres for natural fibre reinforced composites. J Mater Sci 2002;37:1683-92. doi:10.1023/A:1014925621252.

[6] van den Oever MJA, Bos HL, van Kemenade MJJM. Influence of the physical structure of flax fibres on the mechanical properties of flax fibre reinforced polypropylene composites. Appl Compos Mater 2000;7:387-402. doi:10.1023/A:1026594324947.

[7] Andersons J, Poriķe E, Sparniňš E. The effect of mechanical defects on the strength distribution of elementary flax fibres. Compos Sci Technol 2009;69:2152-7. doi:10.1016/j.compscitech.2009.05.010.

[8] Ramesh M. Flax ( Linum usitatissimum L .) fibre reinforced polymer composite materials : A review on preparation, properties and prospects. Prog Mater Sci 2019;102:109-66. doi:10.1016/j.pmatsci.2018.12.004.

[9] Rask M, Madsen B, Sørensen BF, Fife JL, Martyniuk K, Lauridsen EM. In situ observations of microscale damage evolution in unidirectional natural fibre composites. Compos. Part A Appl. Sci. Manuf., vol. 43, Elsevier; 2012, p. 1639-49. doi:10.1016/j.compositesa.2012.02.007.

[10] Kim BW, Nairn J a. Observations of Fiber Fracture and Interfacial Debonding Phenomena Using the Fragmentation Test in Single Fiber Composites. J Compos Mater 2002;36:1825-58. doi:10.1106/002199802026243.

[11] Fraser WA, Ancker FH, Dibenedetto AT, Elbirli B. Evaluation of surface treatments for fibers in composite materials. Polym Compos 1983;4:238-48. doi:10.1002/pc.750040409.

[12] Désarmot G, Favre JP. Advances in pull-out testing and data analysis. Compos Sci Technol 1991;42:151-87. doi:10.1016/0266-3538(91)90016-I.

[13] Desaeger M, Verpoest I. On the use of the micro-indentation test technique to measure the interfacial shear strength of fibre-reinforced polymer composites. Compos Sci Technol 1993;48:215-26. doi:10.1016/0266-3538(93)90139-8.

[14] Wagner HD, Nairn JA, Detassis M. Toughness of interfaces from initial fiber-matrix debonding in a single fiber composite fragmentation test. Appl Compos Mater An Int J Sci Appl Compos Mater 1995;2:107-17. doi:10.1007/BF00569253.

[15] Tripathi D, Jones FR. Single fibre fragmentation test for assessing adhesion in fibre reinforced composites. J Mater Sci 1998;33:1-16. doi:10.1023/A:1004351606897.

[16] Seghini MC, Touchard F, Sarasini F, Chocinski-Arnault L, Mellier D, Tirillò J. Interfacial adhesion assessment in flax/epoxy and in flax/vinylester composites by single yarn fragmentation test: Correlation with micro-CT analysis. Compos Part A Appl Sci Manuf 2018;113:66-75. doi:10.1016/j.compositesa.2018.07.015.

[17] Li X, Tabil LG, Panigrahi S. Chemical Treatments of Natural Fiber for Use in Natural FiberReinforced Composites : A Review. J Polym Environ 2007;15:25-33. doi:10.1007/s10924-006-0042- 
3.

[18] Keener TJ, Stuart RK, Brown TK. Maleated coupling agents for natural fibre composites. Compos. Part A Appl. Sci. Manuf., vol. 35, 2004, p. 357-62. doi:10.1016/j.compositesa.2003.09.014.

[19] Ghaffar SH, Madyan OA, Fan M, Corker J. The Influence of Additives on the Interfacial Bonding Mechanisms Between Natural Fibre and Biopolymer Composites. Macromol Res 2018;26:851-63. doi:10.1007/s13233-018-6119-8.

[20] Arslan C, Dogan M. The effects of silane coupling agents on the mechanical properties of basalt fiber reinforced poly(butylene terephthalate) composites. Compos Part B Eng 2018;146:145-54. doi:10.1016/j.compositesb.2018.04.023.

[21] Le Moigne N, Otazaghine B, Corn S, Angellier-Coussy H, Bergeret A. Modification of the Interface/Interphase in Natural Fibre Reinforced Composites: Treatments and Processes, Springer, Cham; 2018, p. 35-70. doi:10.1007/978-3-319-71410-3_3.

[22] Enciso B, Abenojar J, Martínez MA. Influence of plasma treatment on the adhesion between a polymeric matrix and natural fibres. Cellulose 2017;24:1791-801. doi:10.1007/s10570-017-1209-x.

[23] Van de Weyenberg I, Chi Truong T, Vangrimde B, Verpoest I. Improving the properties of UD flax fibre reinforced composites by applying an alkaline fibre treatment. Compos Part A Appl Sci Manuf 2006;37:1368-76. doi:10.1016/j.compositesa.2005.08.016.

[24] Kalia S, Kaith BS, Kaur I. Pretreatments of Natural Fibers and their Application as Reinforcing Material in Polymer Composites — A Review. Polym Eng Sci 2009. doi:10.1002/pen.

[25] Ali A, Shaker K, Nawab Y, Jabbar M, Hussain T, Militky J, et al. Hydrophobic treatment of natural fibers and their composites - A review. J Ind Text 2018;47:2153-83. doi:10.1177/1528083716654468.

[26] Kaith BS, Singha AS, Kumar S, Kalia S. Mercerization of flax fiber improves the mechanical properties of fiber-reinforced composites. Int J Polym Mater Polym Biomater 2008;57:54-72. doi:10.1080/00914030701328843.

[27] Manikandan Nair KC, Thomas S, Groeninckx G. Thermal and dynamic mechanical analysis of polystyrene composites reinforced with short sisal fibres. Compos Sci Technol 2001;61:2519-29. doi:10.1016/S0266-3538(01)00170-1.

[28] Li Y, Mai YW, Ye L. Effects of fibre surface treatment on fracture-mechanical properties of sisalfibre composites. Compos Interfaces 2005;12:141-63. doi:10.1163/1568554053542151.

[29] Mokoena MA, Djoković V, Luyt AS. Composites of linear low density polyethylene and short sisal fibres: The effects of peroxide treatment. J Mater Sci 2004;39:3403-12.

doi:10.1023/B:JMSC.0000026943.47803.0b.

[30] Ahmad EEM, Luyt AS. Effects of organic peroxide and polymer chain structure on morphology and thermal properties of sisal fibre reinforced polyethylene composites. Compos Part A Appl Sci Manuf 2012;43:703-10. doi:10.1016/j.compositesa.2011.12.011.

[31] Cruz J, Fangueiro R. Surface Modification of Natural Fibers: A Review. Procedia Eng., vol. 155, Elsevier Ltd; 2016, p. 285-8. doi:10.1016/j.proeng.2016.08.030.

[32] Vigneshwaran N. Modification of textile surfaces using nanoparticles. Surf. Modif. Text., Elsevier Inc.; 2009, p. 164-84. doi:10.1533/9781845696689.164.

[33] Yourdkhani M, Liu W, Baril-Gosselin S, Robitaille F, Hubert P. Carbon nanotube-reinforced carbon fibre-epoxy composites manufactured by resin film infusion. Compos Sci Technol 2018;166:169-75. doi:10.1016/j.compscitech.2018.01.006.

[34] Jäger M, Zabihi O, Ahmadi M, Li Q, Depalmeanar A, Naebe M. Nano-enhanced interface in carbon fibre polymer composite using halloysite nanotubes. Compos Part A Appl Sci Manuf 2018;109:115- 
23. doi:10.1016/j.compositesa.2018.03.010.

[35] Abdelal NR, Aljarrah MT. The effect of silicon carbide whiskers on the Mode I interlaminar fracture of carbon fiber composites. Ceram Int 2018;44:2700-8. doi:10.1016/j.ceramint.2017.10.220.

[36] Ma L, Li N, Wu G, Song G, Li X, Han P, et al. Interfacial enhancement of carbon fiber composites by growing $\mathrm{TiO} 2$ nanowires onto amine-based functionalized carbon fiber surface in supercritical water. Appl Surf Sci 2018;433:560-7. doi:10.1016/j.apsusc.2017.10.036.

[37] Logesh G, Rashad M, Lodhe M, Sabu U, Joseph A, James Raju KC, et al. Mechanical and dielectric properties of carbon fiber reinforced reaction bonded silicon nitride composites. J Alloys Compd 2018;767:1083-93. doi:10.1016/j.jallcom.2018.07.208.

[38] Ehlert GJ, Sodano HA. Zinc oxide nanowire interphase for enhanced interfacial strength in lightweight polymer fiber composites. ACS Appl Mater Interfaces 2009;1:1827-33. doi:10.1021/am900376t.

[39] Zhang H, Wang L, Tong JF, Yi XS. Preparation of zinc oxide whisker on carbon fibers. Key Eng Mater 2010;434-435:790-2. doi:10.4028/www.scientific.net/KEM.434-435.790.

[40] Klingshirn CF. ZnO: Material, physics and applications. ChemPhysChem 2007;8:782-803. doi:10.1002/cphc.200700002.

[41] Amin G, Asif MH, Zainelabdin A, Zaman S, Nur O, Willander M. Influence of pH, precursor concentration, growth time, and temperature on the morphology of $\mathrm{ZnO}$ nanostructures grown by the hydrothermal method. J Nanomater 2011;2011. doi:10.1155/2011/269692.

[42] Guo L, Ji YL, Xu H, Simon P, Wu Z. Regularly shaped, single-crystalline ZnO nanorods with wurtzite structure. J Am Chem Soc 2002;124:14864-5. doi:10.1021/ja027947g.

[43] Sharmila PP, Tharayil NJ. Assisted Synthesis, Characterization and Optical Properties of Zinc Oxide Nanoparticles. Int J Mater Sci Eng 2014. doi:10.12720/ijmse.2.2.147-151.

[44] Ding M, Guo Z, Zhou L, Fang X, Zhang L, Zeng L, et al. One-Dimensional Zinc Oxide Nanomaterials for Application in High-Performance Advanced Optoelectronic Devices. Crystals 2018;8:223. doi:10.3390/cryst8050223.

[45] Dakhlaoui A, Jendoubi M, Smiri LS, Kanaev A, Jouini N. Synthesis, characterization and optical properties of $\mathrm{ZnO}$ nanoparticles with controlled size and morphology. J Cryst Growth 2009;311:3989-96. doi:10.1016/j.jcrysgro.2009.06.028.

[46] Talebian N, Amininezhad SM, Doudi M. Controllable synthesis of $\mathrm{ZnO}$ nanoparticles and their morphology-dependent antibacterial and optical properties. J Photochem Photobiol B Biol 2013;120:66-73. doi:10.1016/j.jphotobiol.2013.01.004.

[47] Lee $\mathrm{CH}$, Choi MS. Effects of the deposition condition on the microstructure and properties of $\mathrm{ZnO}$ thin films deposited by metal organic chemical vapor deposition with ultrasonic nebulization. Thin Solid Films 2016;605:157-62. doi:10.1016/j.tsf.2015.09.050.

[48] Nicolay S, Fay S, Ballif C. Growth Model of MOCVD Polycrystalline ZnO. Cryst Growth Des 2009;9:4957-62. doi:10.1021/cg900732h.

[49] Zheng MJ, Zhang LD, Li GH, Shen WZ. Fabrication and optical properties of large-scale uniform zinc oxide nanowire arrays by one-step electrochemical deposition technique. Chem Phys Lett 2002;363:123-8. doi:10.1016/S0009-2614(02)01106-5.

[50] Zeng H, Cui J, Cao B, Gibson U, Bando Y, Golberg D. Electrochemical deposition of ZnO nanowire arrays: Organization, doping, and properties. Sci Adv Mater 2010;2:336-58. doi:10.1166/sam.2010.1096.

[51] Sato Y, Yanagisawa K, Oka N, Nakamura S, Shigesato Y. Sputter deposition of Al-doped ZnO films with various incident angles. J Vac Sci Technol A Vacuum, Surfaces, Film 2009;27:1166-71. 
doi:10.1116/1.3186618.

[52] Mosnier JP, O’Haire RJ, McGlynn E, Henry MO, McDonnell SJ, Boyle MA, et al. ZnO films grown by pulsed-laser deposition on soda lime glass substrates for the ultraviolet inactivation of Staphylococcus epidermidis biofilms. Sci Technol Adv Mater 2009;10:045003. doi:10.1088/14686996/10/4/045003.

[53] Sōmiya S, Roy R. Hydrothermal synthesis of fine oxide powders. Bull Mater Sci 2000;23:453-60. doi:10.1007/BF02903883.

[54] Xu HY, Wang H, Zhang YC, He WL, Zhu MK, Wang B, et al. Hydrothermal synthesis of zinc oxide powders with controllable morphology. Ceram Int 2004;30:93-7. doi:10.1016/S0272-8842(03)000695 .

[55] Baruah S, Thanachayanont C, Dutta J. Growth of $\mathrm{ZnO}$ nanowires on nonwoven polyethylene fibers. Sci Technol Adv Mater 2008;9. doi:10.1088/1468-6996/9/2/025009.

[56] Galan U, Lin Y, Ehlert GJ, Sodano HA. Effect of ZnO nanowire morphology on the interfacial strength of nanowire coated carbon fibers. Compos Sci Technol 2011;71:946-54. doi:10.1016/j.compscitech.2011.02.010.

[57] Lin Y, Ehlert G, Sodano HA. Increased interface strength in carbon fiber composites through a ZnO nanowire interphase. Adv Funct Mater 2009;19:2654-60. doi:10.1002/adfm.200900011.

[58] Swaminathan G, Palanisamy C, Chidambaram G, Henri G, Udayagiri C. Enhancing the interfacial strength of glass/epoxy composites using ZnO nanowires. Compos Interfaces 2018;25:151-68. doi:10.1080/09276440.2017.1341790.

[59] Popescu MC, Ungureanu C, Buse E, Nastase F, Tucureanu V, Suchea M, et al. Antibacterial efficiency of cellulose-based fibers covered with $\mathrm{ZnO}$ and $\mathrm{Al} 2 \mathrm{O} 3$ by Atomic Layer Deposition. Appl Surf Sci 2019;481:1287-98. doi:10.1016/j.apsusc.2019.03.268.

[60] Yang C, Han R, Nie M, Wang Q. Interfacial reinforcement mechanism in poly(lactic acid)/natural fiber biocomposites featuring $\mathrm{ZnO}$ nanowires at the interface. Mater Des 2020;186:108332. doi:10.1016/j.matdes.2019.108332.

[61] Chen XY, Ng AMC, Fang F, Djurišić AB, Chan WK, Tam HL, et al. The Influence of the ZnO Seed Layer on the ZnO Nanorod/GaN LEDs. J Electrochem Soc 2010;157:H308. doi:10.1149/1.3282743.

[62] Song J, Lim S. Effect of seed layer on the growth of ZnO nanorods. J Phys Chem C 2007;111:596600. doi:10.1021/jp0655017.

[63] Chevalier-César C, Capochichi-Gnambodoe M, Leprince-Wang Y. Growth mechanism studies of ZnO nanowire arrays via hydrothermal method. Appl Phys A Mater Sci Process 2014;115:953-60. doi:10.1007/s00339-013-7908-8.

[64] Joffe R, Andersons J, Wallström L. Interfacial shear strength of flax fiber/thermoset polymers estimated by fiber fragmentation tests. J. Mater. Sci., vol. 40, Springer; 2005, p. 2721-2. doi:10.1007/s10853-005-2115-4.

[65] Greene LE, Law M, Tan DH, Montano M, Goldberger J, Somorjai G, et al. General Route to Vertical ZnO Nanowire Arrays Using Textured ZnO Seeds. Nano Lett 2019;5:7. doi:10.1021/n1050788p.

[66] Zhao H, Kwak JH, Conrad Zhang Z, Brown HM, Arey BW, Holladay JE. Studying cellulose fiber structure by SEM, XRD, NMR and acid hydrolysis. Carbohydr Polym 2007;68:235-41. doi:10.1016/j.carbpol.2006.12.013.

[67] Cheng B, Samulski ET. Hydrothermal synthesis of one-dimesional $\mathrm{ZnO}$ nanostructures with different aspect ratios. Chem Commun 2004:986-7. doi:10.1039/b316435g.

[68] Rusu DI, Rusu GG, Luca D. Structural characteristics and optical properties of thermally oxidized zinc films. Acta Phys Pol A 2011;119:850-6. doi:10.12693/APhysPolA.119.850. 
[69] Vayssieres L. Growth of arrayed nanorods and nanowires of $\mathrm{ZnO}$ from aqueous solutions. Adv Mater 2003;15:464-6. doi:10.1002/adma.200390108.

[70] George J, Klompen ETJ, Peijs T. Thermal degradation of green and upgraded flax fibres. vol. 10. 2001.

[71] Arfaoui MA, Dolez PI, Dubé M, David. Development and characterization of a hydrophobic treatment for jute fibres based on zinc oxide nanoparticles and a fatty acid. Appl Surf Sci 2017;397:19-29. doi:10.1016/j.apsusc.2016.11.085.

[72] Stamboulis A, Baillie CA, Peijs T. Effects of environmental conditions on mechanical and physical properties of flax fibers. Compos - Part A Appl Sci Manuf 2001;32:1105-15. doi:10.1016/S1359$835 \mathrm{X}(01) 00032-\mathrm{X}$.

[73] Yan L, Chouw N, Jayaraman K. Flax fibre and its composites - A review. Compos Part B Eng 2014;56:296-317. doi:10.1016/j.compositesb.2013.08.014.

[74] Zafeiropoulos NE. On the use of single fibre composites testing to characterise the interface in natural fibre composites. Compos Interfaces 2007;14:807-20. doi:10.1163/156855407782106438.

[75] Kelly A, Tyson WR. Tensile properties of fibre-reinforced metals: Copper/tungsten and copper/molybdenum. J Mech Phys Solids 1965;13:329-50. doi:10.1016/0022-5096(65)90035-9.

[76] El Asloun M, Donnet JB, Guilpain G, Nardin M, Schultz J. On the estimation of the tensile strength of carbon fibres at short lengths. J Mater Sci 1989;24:3504-10. doi:10.1007/BF02385732.

[77] Seghini MC, Touchard F, Sarasini F, Chocinski-Arnault L, Tirillò J, Bracciale MP, et al. Effects of oxygen and tetravinylsilane plasma treatments on mechanical and interfacial properties of flax yarns in thermoset matrix composites. Cellulose 2020;27:511-30. doi:10.1007/s10570-019-02785-3.

[78] Seghini MC, Touchard F, Chocinski-Arnault L, Placet V, François C, Plasseraud L, et al. Environmentally friendly surface modification treatment of flax fibers by supercritical carbon dioxide. Molecules 2020;25:438. doi:10.3390/molecules25030438.

[79] Ehlert GJ, Galan U, Sodano HA. Role of Surface Chemistry in Adhesion between ZnO Nanowires and Carbon Fibers in Hybrid Composites. ACS Appl Mater Interfaces 2013;5:635-45. doi:10.1021/am302060v. 